\title{
Negative body image in breast cancer patients
}

\author{
Agata Kołodziejczyk ${ }^{1, A, D-F}$, Tomasz Pawłowski ${ }^{2, A, D-F}$ \\ ${ }^{1}$ Lower-Silesian Oncology Centre, Wrocław, Poland \\ 2 Division of Psychotherapy and Psychosomatic Medicine, Department of Psychiatry, Wroclaw Medical University, Poland \\ A - research concept and design; $\mathrm{B}$ - collection and/or assembly of data; $\mathrm{C}$ - data analysis and interpretation; \\ $D$ - writing the article; $E$ - critical revision of the article; $F$ - final approval of the article
}

\section{Address for correspondence}

Tomasz Pawłowski

E-mail: tomasz.pawlowski@umed.wroc.pl

Funding sources

None declared

\section{Conflict of interest}

None declared

Received on January 11, 2019

Reviewed on January 23, 2019

Accepted on February 3, 2019

Published online on February 26, 2019

\begin{abstract}
The aim of this overview study is to familiarize readers with the impact of changes to body image (BI) among patients treated for breast cancer. Body image is subjected to many changes during oncological treatment and every method of treatment (surgery, chemotherapy, radiotherapy, and hormone therapy) can have a negative impact on the way the treated patients perceive their bodies. The article differentiates the susceptibility of patients to a worsened self-image due to their pre-disease personality, socioeconomic factors, age, and declared sense of control during the oncological treatment. Herein, the areas of patients' lives which are the most affected by negative Bl are discussed: quality of life and functioning in society, with particular emphasis on the return to work and sexuality. The ways of protecting patients' BI throughout treatment which have been proposed in the literature are presented in conclusions.
\end{abstract}

Key words: breast cancer, body image, posttraumatic growth
Cite as

Kołodziejczyk A, Pawłowski T. Negative body image in breast cancer patients. Adv Clin Exp Med. 2019;28(8): 1137-1142. doi:10.17219/acem/103626

DOI

10.17219/acem/103626

\section{Copyright}

Copyright by Author(s)

This is an article distributed under the terms of the

Creative Commons Attribution Non-Commercial License

(http://creativecommons.org/licenses/by-nc-nd/3.0/) 


\section{Introduction}

The aim of this paper is to outline the problem of worsening body image (BI) among women treated for breast cancer. Body image in oncological disease is susceptible to many disturbing changes, which are often overlooked since issues of $\mathrm{BI}$ are treated as secondary to the fight for life and health. However, it cannot be overlooked that patients treated for breast cancer experience many negative changes in relation to body self already during the treatment and after the end of treatment they struggle with the effects of less positive self-perception. ${ }^{1,2}$ Negative BI has a significant impact on the quality of life, sexuality and social functioning of patients. In addition, it may become an obstacle to posttraumatic growth (PTG).

Posttraumatic growth refers to all of the positive outcomes that arise as a result of stressful, life-threatening experiences. ${ }^{3}$ Expected signs of PTG can include a change in philosophy or lifestyle, developments in interpersonal relationships, or a sense of increased effectiveness. The following factors are thought to determine the occurrence of PTG: personality factors, the specifics of the stressful situation, support, emotions, behaviors related to dealing with the disease, and strategies of coping with stress. ${ }^{4,5}$ It can be considered whether patients' susceptibility to changes in BI could be another variable that may influence the occurrence of PTG. Therefore, this paper and further research could be important in contributing to the support of oncological patients in this aspect.

There are many definitions of BI, but each of them focuses on the role of one's corporeality in shaping one's sense of identity - the body self. Paul Schilder described $\mathrm{BI}$ in the most literal way: he defined BI as a conception, an image of one's own body created in the mind. ${ }^{6}$ Many psychological theories, with the psychodynamic approach at the forefront, also raised the issue of $\mathrm{BI}^{7} \mathrm{~A}$ representative of this approach in psychology, David Krueger, ${ }^{8}$ drew attention to the essence of BI in the "creation" of a person, in building one's identity with reference both to selfperception and to the functions of the body. Another theorist of $\mathrm{BI}$, Alexander Lowen, ${ }^{9}$ in referring to the vital role of BI in our lives, created the concept of a "betrayal" of the body. This concept, referring to the feeling of losing control over one's own body, a lack of acceptance of one's body, and negative emotions towards oneself, is applicable to patients treated for breast cancer. Frank Rohrich's concept completes the definition of BI. ${ }^{7}$ He divides experiences related to the body into perception - namely, perception of the body - a cognitive approach to the body, emotions, and specific behaviors related to the body. We present this division to draw attention to the multifaceted nature of potential problems that may result from a disturbed BI.

The multidimensionality of $\mathrm{BI}$ is also reflected in the instruments developed to measure this construct. The 2 most commonly used instruments are the Body Esteem Scale, referring directly to the psychodynamic tradition, ${ }^{7}$ and the Multidimensional Body-Self Relation Questionnaire, representing the cognitive point of view. ${ }^{26}$

To emphasize more strongly the importance of BI in oncological disease, we would like to highlight the variability of identity during the illness. Changes to the body can contribute to a decline in self-esteem, a deterioration of mood and irrational beliefs about oneself. The changing body is also a symbol of the disease; it becomes equated with the cultural image of the disease. ${ }^{1}$ A body consumed by disease, which does not fit the contemporary canonical ideals, becomes a source of negative emotions.

This paper aims to show the changes that occur in the bodies of women treated for breast cancer and the problems that may arise from the resulting changes in BI. It will focus on factors that can differentiate patients in terms of changes in the BI, as well as in the areas most affected by these changes.

\section{Breast cancer and changes in the body}

In light of advancements in medicine today, it can be said that there is a huge variety of treatments for breast cancer. Within the 4 basic oncological procedures - namely, surgery, chemotherapy, radiotherapy, and hormone therapy - there will be a lot of changes in the body, the effects of which the patients will have to deal with.

\section{Changes in the body after surgery}

Nowadays, surgery is one of the most commonly used methods of breast cancer treatment. There are many variants of breast cancer surgery and each of them leaves the woman's body mutilated to some extent. In contrast to procedures standard 10-15 years ago, bilateral mastectomy is a rarity. This is a positive development which is supported by the studies by Rosenberg et al. in which they found that after this very surgery patients reported the most negative $\mathrm{BI} .{ }^{10}$ Other variants of this procedure are breastsaving surgery, unilateral mastectomy or mastectomy with reconstruction. An important variable of each of these treatments is the extent to which the disease has spread to the lymph nodes. ${ }^{11}$ Each of these surgeries can cause many difficulties. Each one more or less requires patients to deal with remnants of the surgery, such as postoperative scars, foreign bodies like surgical drains, swelling, redness, lymphedema, and others. All of them may result in severe pain causing, e.g., worsened cognitive functioning or depressed mood, leading to a deterioration in quality of life.

However, the aesthetic aspect of such treatments is also important. Depending on the severity of the disease, the extent of changes, as well as the skills and experience of surgeons, the effect of the surgery may differ and the patient may have problems accepting the asymmetry of the breasts, the disproportion between them or the need 
to wear bra pads to comfortably display cleavage. ${ }^{12}$ It can cause problems with self-acceptance, but may also result in problems concerning sexuality and the quality of one's relationships.

With the steady progress of treatment methods and the increasing frequency of breast reconstruction surgeries, problems can be expected with the "new" BI among patients with implants. Such surgery may be associated with unnatural sensations in the reconstructed breast, a sense of artificiality, or even the potential for the implant to be rejected. ${ }^{13}$ Psychological problems stem from patients' prolonged stress over beliefs of what is normal and what may be alarming during convalescence. It also can lead to indirect problems accepting one's "new" body and engaging in intimate relations.

Finally, it should be remembered that each of the surgical procedures is associated with pain, redness and swelling in the surgical field, which can also negatively affect the patients' well-being in relation to their perception of own bodies. In our professional practice, we find that patients often do not want to see their breasts after the surgery and they look away while changing clothes in order to avoid doing so. From a psychological point of view, it poses the question of how long a patient can reject their post-surgery body and what will confronting it mean for the patient's mood or cognitive and social functioning.

\section{Changes in the body after chemotherapy}

Chemotherapy is one of the treatments for breast cancer with perhaps the most prominent side effects which greatly impact the patients' appearance and, thus, have a very negative effect on their BI. ${ }^{1}$

The side effect that is most associated with chemotherapy treatment is hair loss. ${ }^{1}$ Even the loss of hair on the head alone is often a traumatic experience for the patient. ${ }^{14}$ Studies show that patients' assessment of their BI after chemotherapy worsens dramatically, mainly due to the need to wear wigs or headscarves. ${ }^{2}$ There are many consequences, ranging from a decrease in self-esteem or a decreased sense of sexuality and attractiveness to social difficulties and relationship problems. ${ }^{14}$ However, it should be remembered that hair loss during chemotherapy does not apply only to the hair on one's head. As the treatment progresses, the patients can lose their eyebrows, eyelashes, nasal hair, and pubic hair. The loss of hair in the nose leads to complications such as nosebleeds and discomfort in breathing. Eyes without eyelashes are more difficult to open and more susceptible to infection and dirt. A lack of pubic hair can lead to irritation of one's intimate parts and problems with urination. ${ }^{1}$

It should be noted that physical difficulties are often related to psychological deterioration. In this case, sexual disorders, relationship problems, a lack of self-satisfaction, and negative beliefs about oneself should be considered, among other things.
In addition to the problems resulting from hair loss, chemotherapy can also contribute to weight loss. This may be due to the decreased appetite, nausea, frequent vomiting, loss of energy, and drowsiness associated with this type of treatment. The opposite situation may occur, as well. Cytostatic therapy may contribute to weight gain, especially if steroids are also used.

Other changes in the body occurring during chemotherapy include increased perspiration, changes in facial features, brittle or blackened fingernails resulting from fungal infection, oral fungal infections, and complexion problems, such as an earthy or unhealthy complexion. This often leads to low moods, anxiety and feelings of shame, causing patients to stay at home or to neglect some of their duties.

\section{Changes in the body after radiotherapy}

Radiotherapy has a different effect on the appearance of the body. Possible consequences include burns, skin irritation, edema, radiation scars and reactions, and inflamed and festering wounds. It should also be taken into account that radiotherapy is a long treatment (4-6 weeks), causing fatigue and discomfort, which can also negatively affect the sense of attractiveness and cause psychological distress.

\section{Changes in the body after hormone therapy}

Hormone therapy is more and more frequently used to complement the main treatment. In order to understand the changes that occur in a woman's body while taking hormonal drugs, patients should be divided into 2 groups: pre- and postmenopausal. Before starting treatment, postmenopausal patients are asked to discontinue use of any hormonal drugs that are intended to reduce the symptoms of menopause. As a result, patients see a return of symptoms such as hyperhidrosis, hot flashes, irritability, weight gain, vaginal dryness, and others. ${ }^{15}$ Moreover, patients confront many psychological disturbances connected with common beliefs about menopause. It often causes women to feel older, less socially and physically attractive, and more frustrated and depressed. These symptoms may persist throughout the whole duration of the hormone therapy, i.e., up to 10 years after the main treatment ends.

The use of hormone therapy in patients who have not yet reached menopause should be considered differently. In their case, hormone therapy hastens the onset of menopause. In this situation, patients struggle with the same symptoms as postmenopausal patients. Additionally, hastened menopause causes infertility. Therefore, patients in the prime of their lives often stop feeling attractive, suffer lower self-esteem ${ }^{16}$ and are sometimes put into a situation where they must accept that they will not have any more children or will not be able to have children at all, which impacts their mental and overall well-being, often causing 
symptoms of depression and anxiety resulting from beliefs about not fulfilling women's "social and natural duty".

To conclude, oncological treatment of breast cancer can significantly affect a woman's BI. ${ }^{11}$ There are as many problems potentially resulting from different types of treatment as there are treatment options. Which problems will occur depends largely on the individual characteristics of each patient.

\section{Variability of body image in patients treated for breast cancer}

Not every patient will declare the same extent of worsened BI due to changes resulting from oncological treatment. Numerous studies report that there are many variables that determine how patients cope with the changes in their body and how it affects their functioning during treatment and after the disease. ${ }^{17}$ We will present 4 areas that may affect how patients see their bodies affected by breast cancer: the patients' pre-disease personality, socioeconomic factors and common knowledge about cancers prior to treatment, patients' age, and the sense of control reported during treatment.

\section{Pre-disease personality and perception of body changes}

The personality of the patient before her disease will have a big impact on how she feels about the changes in her body once treatment ends. ${ }^{18}$ The patient's identity is put to the test in expanding it to the image of the diseased self while dealing with all the changes resulting from such a crisis. Studies report that changes in the BI of patients who have completed breast cancer treatment largely depend on their BI before the disease. From the data provided by Rhondali et al., ${ }^{18}$ it appears that patients who had a positive BI prior to their disease deal with the changes that result from treatment better than the patients who initially reported a negative BI. In addition, the same studies claim that patients who initially declare a negative BI show more symptoms of depression during cancer treatment. Patients who find it harder to observe changes in their body have difficulty looking in the mirror. Patients describe the hair loss resulting from chemotherapy as a particularly difficult experience. ${ }^{14}$ According to some studies, patients who do not deal well with changes to their BI experience a decrease in self-esteem. ${ }^{2}$ The changing BI impacts on their identity and destroys the often unstable balance and self-image. Patients evaluate the changes in the body as a reminder of the disease, something that prevents them from forgetting that they are ill, that an inseparable part of their identity is the sense of a diseased self. ${ }^{1}$

There are also reports which state that the ability to deal with emotions before the disease will affect the extent of changes to the BI. ${ }^{18}$ More stable patients who cope better with their feelings will suffer less from the changing BI than emotionally unstable patients with disordered identities.

\section{Socioeconomic factors and public views on oncological disease}

A very important factor influencing whether or not patients will negatively assess changes within their body is their socioeconomic status and public views on oncological treatment. ${ }^{19}$ Studies show that socioeconomic status, education and employment play a role in BI disorders. The study group of Chang et al. ${ }^{19}$ proves that employment and higher education will contribute to lower self-esteem once treatment ends. They also state that a higher per capita income in the patient's family heralds a better BI for the patient. The first conclusion can be explained by the greater awareness among patients with higher education of the consequences of cancer treatment and by the fear associated with returning to work, a fear associated with rejection and ostracism and reported by many women who have completed oncological treatment. ${ }^{19}$ This fear is worsened by widespread, inaccurate public beliefs about the disease. As a result, patients' readjustment to life after the disease is very difficult and the changes to their $\mathrm{BI}$ are a painful reminder that after treatment they will stand out and thus be exposed to many unpleasant social situations. Many patients do not want their appearance to embarrass others, ${ }^{2}$ nor do they want to be treated differently than others. For this reason, women often refrain from leaving the house after oncological treatment. Both their social and professional lives suffer because of this trepidation. ${ }^{14}$

On the other hand, a higher socioeconomic status means that patients have a greater ability to mask changes in their body which may contribute to their well-being. Such patients may, i.e., buy a wig made from real hair or may begin treatment in more specialized clinics equipped with cooling caps, or they can make use of better cosmetics, etc. to take more control over their appearance.

\section{Patients' age and changes in body image}

Another key factor that can bring about changes in BI is age. Studies show that younger patients do not deal with oncological treatment and its consequences as well as older patients. ${ }^{20}$ Studies by Janz et al. prove that younger patients are less well-adjusted mentally to crises such as cancer. ${ }^{12}$ Such conclusions are supported by studies from Miller et al., ${ }^{21}$ which show that younger women experience more preoperative stress than older women. The same studies show that BI in younger patients will be completely different and, therefore, it will change in different ways as a result of the treatment methods used. A patient's young age may indicate more radical treatment methods and thus is more likely to increase the stress associated with serious 
changes to the body. For example, chemotherapy, which has the worst associations in society as well as the most negative assessments from oncology patients, is used more frequently in young patients. ${ }^{1}$ Moreover, there are studies which prove that young patients who initially had a negative BI will cope with cancer treatment worse than older patients with an equally negative self-image. ${ }^{13}$

One may suspect that a worse BI in young women may result from problems of both physical and psychological nature. Struggling at a young age with physical limitations, a decreased sense of attractiveness, lowered self-esteem, or deliberations on the impact of treatment on one's future is extremely burdensome; the body is exhausted by disease and its transformation reminds patients of the disease, so there is an extremely negative impact on young women and their BI.

\section{Sense of control during the treatment and body image}

The last factor affecting the differences in BI among patients after completing cancer treatment is the subjective sense of control during treatment. Studies by Chang et al. show that patients who reported a sense of influence over the decisions regarding their treatment coped better with their treatment and, thus, with the changes to their body resulting from the treatment they chose. ${ }^{19}$

Other studies show a hierarchy of well-being, depending on the type of surgery, reporting that patients who decided to have breast reconstruction had a less negative BI than patients who underwent mastectomy. ${ }^{16}$

\section{The influence on social functioning of a negative body image during oncological treatment}

Among the many aspects of the lives of patients treated for breast cancer which are affected by their worsened BI, the subject literature seems to focus in particular on 3 basic ones: quality of life, sexuality and social functioning.

As the most general construct covering many aspects of life, quality of life was included in many studies. ${ }^{12,19,22}$ The overview study by Lemieux et al. includes the issue of quality of life among patients treated with chemotherapy for breast cancer. ${ }^{1}$ They recognized anxiety symptoms, a general feeling of stress, sexuality, self-esteem, social functioning, and the return to work as part of quality of life. Patients reported problems in all of these aspects. It turned out that patients treated with chemotherapy reported particularly low results on the life quality scale. They also reported the largest decrease in sexuality due to the treatment. Other studies ${ }^{10}$ focused on physical and psychosocial functioning, partner interactions, sexual functioning, and medical interactions. All of these categories can be said to describe the quality of life. The results of these studies indicated that patients who underwent breast cancer treatment felt uncomfortable with the changes in their bodies, felt embarrassed to show others a body affected by disease and were particularly uncomfortable showing others their postoperative scars.

Another area significantly affected by negative BI after oncological treatment is social functioning. According to reports, ${ }^{2}$ patients are extremely stressed by society's reception of changes in the body and have great difficulty readapting to life in society after their treatment. Another study confirmed this deterioration in the social life of patients after treatment. ${ }^{19}$ In these studies, patients reported grave concerns about making others embarrassed because of their appearance. Many studies also emphasize the difficulties patients have leaving the house after treatment. ${ }^{1}$ This may be due to symptoms of depression caused by their negative $\mathrm{BI}$, reluctance to admit to having the disease, or fear of social ostracism or other negative reactions from society. ${ }^{23}$ Studies also point to another particularly important aspect of social life - returning to work. It turns out that patients report feeling a huge amount of stress associated with returning to their duties. ${ }^{1}$ This is expressed, e.g., by the problem of getting dressed for work in such a way as to feel comfortable yet not to draw attention to oneself.

The conclusion that follows from these considerations is that many patients treated for breast cancer experience negative changes to their BI, changes which affect their functioning in society, family life and quality of life. For this reason, this issue should be addressed globally and the research should focus on how to prevent the negative impact to the BI of patients suffering from breast cancer.

\section{Summary}

There are many areas of life that can be negatively affected by changes in BI. Many of the studies and articles quoted above conclude that it is important to take care of the BI of patients suffering from breast cancer. The most general argument is the influence that BI has on the patients' quality of life. This can include social functioning, well-being, sexuality, satisfaction with relationships, etc.

An analysis of the presented articles suggests that work on patients' BI should be applied at 3 stages of treatment: at the beginning of, during and after the main treatment.

Focusing on BI before starting treatment could prepare patients for the treatment outcomes and the changes that await them. Studies ${ }^{24}$ have proven that a worse initial BI in patients indicates further deterioration in well-being throughout treatment. Therefore, it is worth working on the patients' BI before treatment. On the other hand, as shown in the presented material, it seems worth trying to increase social awareness of cancer and its consequences. This would aim to change the perceptions of people who are ill, and thus to ensure that they do not develop a sense of rejection and alienation due to their disease. It seems all the more important that we learn from 
some studies that there is a group of people who choose not to undergo cancer treatment because of the changes in the body resulting from chemotherapy. ${ }^{1}$

Other studies point out that among cancer patients, the negative BI persisted for 12 weeks or longer after the end of treatment. ${ }^{24,25}$ This proves the importance of working on the patients' BI during and after treatment. The effect of such work would be to limit the negative effects of changes to the patients' BI and perhaps to create space for PTG, which is a desirable outcome for patients completing oncological treatment. A negative BI can be a powerful obstacle to PTG. ${ }^{3,4}$

\section{ORCID iDs}

Agata Kolodziejczyk (1) https://orcid.org/0000-0002-8498-8049 Tomasz Pawłowski (1) https://orcid.org/0000-0002-3997-609X

\section{References}

1. Lemieux J, Mausell E, Provencher L. Chemotherapy-induced alopecia and effects on quality of life among women with breast cancer: A literature review. Psychooncology. 2008;17(4):317-328.

2. Garcia SN, de Castro Figueiredo Pereira Coelho R, Dias dos Santos PN, Alves Maftum M, de Fatime Mantovani M, Puchaliski Kalinke L. Changes in social function and body image in women diagnosed with breast cancer undergoing chemotherapy. Acta Scientiarum. Health Sciences. 2017;39(1):57-64.

3. Danhauer SC, Case LD, Tedeschi R, et al. Predictors of posttraumatic growth in women with breast cancer. Psychooncology. 2013;22(12):1-15.

4. Inan FS, Ustun B. Breast cancer and posttraumatic growth. J Breast Health. 2014;10(2):75-78.

5. Chow YK, Masiak J, Mikołajewska E, et al. Limbic brain structures and burnout: A systematic review. Adv Med Sci. 2018;63(1):192-198.

6. Schielder P. The image and appearance of the human body: Studies in the constructive energies of the psyche. London, UK: Paul Kegan; 1935.

7. Schier K. Dorosłe dzieci. Psychologiczna problematyka odwrócenia ról w rodzinie. Warszawa, Poland:Wydawnictwo Naukowe SCHOLAR;2014.

8. Krueger DW. Psychodynamic perspectives on body image. In: Cash TF, Pruzinsky T, eds. Body Image: A Handbook of Theory, Research and Clinical Practice. New York, NY: Guilford Press; 2002:30-37.

9. Lowen A. Zdrada ciała. Koszalin, Poland: Ośrodek Bioenergetycznej Pracy z Ciałem, Pomocy i Edukacji Psychologicznej; 2011.

10. Rosenberg, SM, Tamimi RM, Gelber S, et al. Body image in recently diagnosed young women with early breast cancer. Psychooncology. 2013;22(8):1849-1855.

11. Morone G, losa M, Fusco A, et al. Effects of a multidisciplinary educational rehabilitative intervention in breast cancer survivors: The role of body image on quality of life outcomes. ScientificWorldJournal. 2014;1-11.
12. Janz NK, Mujahid M, Lantz PM, et al. Population-based study of the relationship of treatment and sociodemographics on quality of life for early stage breast cancer. Qual Life Res. 2005;14(6):1467-1479. https://doi.org/10.1007/s11136-005-0288-6

13. Schover LR, Yetman RJ, Tuason LJ, Meisler E, Esselstyn CB, Hermann RE. Partial mastectomy and breast reconstruction: $A$ comparison of their effects on psychosocial adjustment, body image and sexuality. Cancer. 1995;75(1):54-64.

14. Kim IR, Cho J, Choi EK, et al. Perception, attitudes, preparedness and experience of chemotherapy-induced alopecia among breast cancer patients: A qualitative study. Asian Pac J Cancer Prev. 2012;13(4): 1383-1388.

15. Pacian A, Kulik TB, Chruściel P, Pacian J, Skórzyńska H, Zakrzewska W. Uwarunkowania psychospołeczne jakości życia kobiet w okresie klimakterium leczonych z powodu raka piersi. Prz Menopauzalny. 2012; 5:423-427.

16. Fobair P, Stewart SL, CHang S, D'Onofrio C, Banks PJ, Bloom JR. Body image and sexual problems in young women with breast cancer. Psychooncology. 2006;15(7):579-594.

17. Rezaei M, Elyasi F, Janbabai G, Moosazadeh M, Hamzehgardeshi Z. Factors influencing body image in women with breast cancer: A comprehensive literature review. Iran Red Crescent Med J. 2016;18(10):1-9.

18. Rhondali W, Chisholm GB, Filbet M, et al. Screening for body image dissatisfaction in patients with advanced cancer: A pilot study. $\mathrm{JPal}$ liat Med. 2015;18(2):153-156.

19. Chang O, Choi EK, Kim IR, et al. Association between socioeconomic status and altered appearance distress, body image and quality of life among breast cancer patients. Asian Pac J Cancer Prev. 2014;15(20): 8607-8612.

20. Paterson C, Lengacher CA, Donovan KA, Kip KE, Tofthagen CS. Body image in younger breast cancer survivors: A systematic review. Cancer Nurs. 2016;39(1):39-58.

21. Miller SJ, Schnur JB, Weinberger-Litman SL, Montgomery GH. The relationship between body image, age and distress in women facing breast cancer surgery. Palliat Support Care. 2014;12(5):363-367.

22. Kim MK, Kim T, Moon HG, et al. Effect of cosmetic outcome on quality of life after breast cancer surgery. Eur J Surg Oncol. 2015;41(3): 426-432.

23. Nowicki A, Rządkowska B. Depresja i lęk u chorych z nowotworami złośliwymi. Współ Onkol. 2005;9(9):396-403.

24. Rhoten BA, Deng J, Dietrich MS, Murphy B, Ridner SH. Body image and depressive symptoms in patients with head and neck cancer: An important relationship. Support Care Cancer. 2014;22(11):30533060. doi:10.1007/s00520-014-2312-2

25. King MT, Kenny P, Shiell A, Hall J, Boyages J. Quality of life three month and one year after first treatment for early stage breast cancer: Influence of treatment and patient characteristics. Qual Life Res. 2000;9(7):789-800.

26. Cash TF. Cognitive-behavioral perspectives on body image. In: Cash TF, Smolak L eds. Body image: A handbook of science, practice, and prevention. New York, NY: Guilford Press; 2011:39-47. 